\title{
Revolução e educação em Gramsci (1919-1920)
}

Thiago Chagas Oliveira

Doutorando em Educação Brasileira pela Universidade Federal do Ceará

Sandra Cordeiro Felismino

Professora da Universidade Federal do Ceará

\section{Resumo}

Este trabalho toma como objeto de investigação a experiência revolucionária vivida por Antonio Gramsci em 1919/1920. Sustenta a hipótese teóricoinvestigativa segundo a qual os artigos escritos por Gramsci neste período fornecem elementos fundamentais para a compreensão da gênese de suas reflexões sobre trabalho e educação.

Palavras-chave: Gramsci; Revolução; Formação Política.

\begin{abstract}
This work takes as its object of investigation revolutionary experience lived by Antonio Gramsci in 1919/1920. It supports the argument that the articles written by Gramsci in this period provide key elements for understanding the genesis of his reflections on work and education.
\end{abstract}

Keywords: Gramsci; Revolution; Political Education. 
$\mathrm{O}$ s escritos gramscianos que vão de 1916 a 1920 são profundamente marcados pela conjuntura mundial do primeiro quartel do século XX. Eles, de certa forma, sintetizam os problemas, as dúvidas, os anseios e as esperanças do movimento operário no período revolucionário desencadeado com a I Guerra Mundial. Nos textos deste período, Gramsci assinala que, embora o desenvolvimento das forças produtivas capitalistas tenha contribuído para criar um estado comum de miséria, penúria e exploração, o trabalho educativo-cultural de elevação da consciência política das massas é absolutamente fundamental ao desenvolvimento e à sedimentação da consciência de classe dos trabalhadores; conceito que nesta época é definido como o reconhecimento, por parte deles, de seu devir histórico e dos objetivos a serem alcançados com a luta revolucionária.

Os anos de 1919 e 1920 marcam um período histórico em que a esquerda mundial considerava que as possibilidades de sucesso e propagação da revolução bolchevique no ocidente eram iminentes. É nesse contexto de entusiasmo e esperança revolucionária que Gramsci pensa, a partir da atuação dos trabalhadores no local de trabalho, as possibilidades de uma formação política que fosse capaz de prepará-los para administração e controle de todo o processo produtivo. Esse período assume indiscutível importância no desenvolvimento teórico de Gramsci. Spriano (1976, p.12), por exemplo, diz que a maior parte das contribuições para a discussão de seu pensamento político vem deste momento. Destacam-se, sobretudo, as iniciativas educativas e culturais do grupo L'Ordine Nuovo, bem como, o que é particularmente significativo, as experiências de formação política dos conselhos de fábrica.

Se, até 1918, Gramsci acentua a importância de uma atividade cultural complementar capaz de intervir no sentido de fortalecer a luta política e econômica dos trabalhadores, a partir de 1919 ele destacará as possibilidades educativas existentes no seio da classe operária, isto é, no e pelo trabalho. Em 1920, a partir da experiência histórica dos conselhos operários de fábrica de Turim, Gramsci passa a defender a necessidade de 
um trabalho de formação política das massas a partir das possibilidades educativas no próprio processo produtivo. Destarte, a análise desse período contribui significativamente para o entendimento das reflexões de Gramsci acerca da necessidade de unidade orgânica entre a práxis revolucionária da classe trabalhadora e o desenvolvimento de ações pedagógicas capazes de auxiliar o fortalecimento e a combatividade de suas lutas em prol do socialismo.

O fim da I Guerra provocou uma crise profunda na economia mundial ${ }^{1}$. Segundo Hobsbawm (1995, p.43), “em meados da década de 1920, nos quais se pareceu ter deixado para trás a guerra e a perturbação pós-guerra, a economia mundial mergulhou na maior e mais dramática crise que conhecera desde a Revolução Industrial”. Para a Itália, assim como para a maioria dos países europeus que participaram diretamente do conflito, o custo humano da guerra foi brutal: 680 mil mortos; 680 mil prisioneiros; mais de um milhão de feridos; 500 mil mutilados e 600 mil mortos pela gripe espanhola (DIAS, 2000, p.255).

Em Turim, o fim da guerra é concebido de forma preocupante, mormente no que diz respeito ao futuro de amplas massas da população (desemprego, fome, doenças, intensificação da exploração do trabalho etc). Os problemas sociais são ocasionados, principalmente, pelo aumento exorbitante dos preços relativos aos gêneros de primeira necessidade. Entre abril e julho de 1919, por exemplo, os inscritos nas listas de auxílio governamental saltam de aproximadamente de 1.700 a quase 14.000 . Somado a isso, surgem dificuldades próprias de uma cidade que conheceu

\footnotetext{
1 Alguns números atestam os reflexos da crise na Itália: "O processo inflacionário toma proporções imensas. A inflação passa do índice 100 (1913) para 409 (1918). O dólar, que era cotado a 5,18 por lira (1914), passa a 13,07 (1919) e 28,57 (dezembro de 1920). A dívida pública soma no final da guerra 74.496 milhões de liras e o ritmo da indústria cai de 20 a 40\%. O déficit do Estado eleva-se de 214 milhões de liras (1914-1915) para 23.345 milhões (1918-1919). A circulação monetária passa de 2.007 milhões (junho de 1914) para 20 bilhões (dezembro de 1920). Entre 1916 e 1918 cerca de $30 \%$ da renda nacional é obtida a título de empréstimo. A agricultura está em crise: $40 \%$ da balança comercial estão comprometidos com a importação de alimentos." (DIAS, 2000, p.255).
} 
um extraordinário desenvolvimento em razão da atividade econômica bélica. Antes da guerra, a Itália era um país economicamente atrasado.

Com o fim da guerra, surge o problema da "reconversão", isto é, o da necessidade de transformação dos setores bélicos em setores produtivos de outra natureza. Eis aqui o aparecimento de um grave problema: as indústrias que não conseguiam operar tal mudança eram inevitavelmente levadas à falência. A ameaça das falências, somada ao aumento contínuo do custo de vida, não tardou para ocasionar uma situação explosiva na Itália, sobretudo nas cidades mais desenvolvidas (Turim, Milão e Gênova). As contradições do pós-guerra ensejaram conflitos que se manifestaram de modo evidente e contínuo ao longo de todo o primeiro biênio (1919 - 1920); um biênio que em Turim, mais do que nas outras cidades, será marcado pelo acirramento da luta de classes (bienio rosso) (D'ORSI, 2004).

Embora as contradições do pós-guerra fornecessem condições propícias para a tomada do poder, Gramsci ressaltava a idéia de que os revolucionários não deveriam ceder à tentação de destruir por destruir, provocar a desordem pela desordem. Tratava-se, pelo contrário, da elaboração duma nova ordem, fundada, sobretudo, pela: (i) expulsão do capitalista da fábrica, (ii) pelo incremento da produção autogestionária operária, (iii) bem como pelo esforço de realizar um trabalho educativocultural capaz de elevar a consciência de classe do movimento operário italiano (GRAMSCI, 20004c, p. 201 - 226).

Nesse contexto, a atuação de Gramsci no seio do PSI se voltará para a preparação e organização das massas operárias para a revolução. A partir de 1919, suas atividades em torno dos processos de promoção cultural e formação política se intensificam. Destaque-se, em especial, a experiência formativa do jornal de orientação comunista $L^{\prime}$ Ordine Nuovo ${ }^{2}$. Desde suas

\footnotetext{
${ }^{2}$ Os artigos publicados em L'Ordine Nuovo, além de serem indispensáveis para a compreensão dos principais conceitos gramscianos (sobretudo o conceito de hegemonia), fornecem elementos fundamentais para a compreensão da gênese das reflexões de Gramsci sobre trabalho e educação. Defendemos a idéia de que as célebres reflexões sobre os intelectuais e acerca da escola unitária expostas em seu caderno número 12 (Apunti e note sparse per un grupo di saggi sulla storia degli intellettuali) são adequadamente compreendias se cruzadas com os textos publicados em L'Ordine Nuovo. Aliás, o próprio
} 
primeiras publicações, é o porta voz da idéia gramsciana segundo a qual a revolução comunista, para além de um ato meramente insurrecional, é um processo complexo em cuja base deve existir o esforço por parte dos trabalhadores de elaborarem uma consciência de classe fortalecida pela preparação cultural. Não é casual o fato de que no primeiro volume, de 1919, logo no cabeçalho, Gramsci atribua ao proletariado o esforço voltado para a necessidade de instruir-se, para a necessidade da batalha das idéias, do trabalho pedagógico e cultural: "Instruí-vos porque teremos necessidade de toda a vossa inteligência. Agitai-vos porque teremos necessidade de todo o vosso entusiasmo. Organizai-vos porque teremos necessidade de toda vossa força".

Ao fim da segunda metade de 1919, L'Ordine Nuovo se caracterizará como órgão educativo-cultural do movimento dos conselhos de fábrica ${ }^{3}$. A atividade desenvolvida pelo jornal demonstra a tese de que os trabalhos de formação política contribuem para o processo de elevação da consciência de classe dos trabalhadores, na medida em que correspondem às necessidades postas pelo movimento operário, isto é, quando são capazes de concretizar uma aspiração já latente na consciência das massas trabalhadoras. Segundo o relato de Vincenzo Bianco, operário que participou da ocupação das fábricas no biênio 1919/1920, L'Ordine Nuovo fazia sucesso entre os trabalhadores porque era um jornal dirigido aos operários e falava de coisas que lhes interessavam: "era um jornal diferente dos outros, tratava problemas que os outros periódicos não tratavam e vinha ao encontro de nossas necessidades de estudar.'(Apud D’ORSI, 2004, p.71). De fato, a

Gramsci corrobora tal posicionamento, quando assinala que: "No mundo moderno, a educação técnica, estreitamente ligada ao trabalho industrial, mesmo o mais primitivo e desqualificado, deve constituir a base do novo tipo de intelectual. Neste sentido trabalhou o semanário L'Ordine Nuovo, visando desenvolver certas formas de novo intelectualismo e a determinar seus novos conceitos; e essa não foi uma das razões menores de seu êxito, pois uma tal colocação correspondia a aspirações latentes e era adequada ao desenvolvimento das formas reais de vida." (Grifos nossos, 1975, p.1551).

${ }^{3}$ Segundo Schlesener: "Os conselhos [...] organizam-se no interior das fábricas com uma conformação específica que unia o ato da produção e o exercício da soberania, com a finalidade de desenvolver uma nova concepção de Estado. [...] tinham uma característica inovadora que se produzia no fato de se apresentarem como uma forma organizativa que aliava e inter-relacionava o trabalho produtivo, a política e a educação.” (2005, p.39).

(C) Filosofia e Educação (Online), ISSN 1984-9605 - Revista Digital do Paideia 299 Volume 2, Número 1, Abril-Setembro de 2010 
idéia de Gramsci era a de auxiliar os operários a crescerem e a apropriaremse de instrumentos intelectuais, sem menosprezar, todavia, a constatação de que eles aprendem a partir de suas experiências e lutas cotidianas.

A importância do trabalho de formação política de L'Ordine Nuovo, segundo avalia o próprio Gramsci (2004c, p.204), é o de ter conseguido escutar as vozes do mundo do trabalho e de saber interpretá-las de acordo com as necessidades mais prementes do movimento operário (GRAMSCI, 2004a, p.404).

Ao resumir a linha editorial do jornal, Gramsci deixa claro que: "A constituição do Estado Operário deve fundar-se na fábrica, deve fundar-se na organização operária de fábrica de modo que o poder industrial, que hoje pertence aos proprietários privados, possa se transferir para outras mãos." (2004c, p.204). Nesse período, a argumentação gramsciana aponta para a defesa de um ordenamento econômico-político que articule a justiça autêntica com a eficiência produtiva, a democracia com o autogoverno dos produtores.

É bem verdade que, após um ano da fundação do jornal, Gramsci traçará um balanço crítico que reduz sua primeira semana de publicação ao produto de um medíocre intelectualismo animado apenas pela boa vontade e por vagos propósitos. Em sua crítica perguntava-se: “Quem éramos? Quem representávamos? De que nova palavra éramos portadores?” Como o próprio Gramsci reconhecerá mais tarde, contudo, L'Ordine Nuovo se transformará no motor do movimento dos conselhos de fábrica; uma arma política e ideológica que tinha o propósito de fazer o proletariado adquirir, na prática revolucionária, uma consciência de classe dirigente. No sétimo número de L’Ordine Nuovo, no célebre artigo Democrazia Operaia, Gramsci apresenta, de forma explícita, a problemática central do jornal: "Como ligar o presente ao futuro, satisfazendo as urgentes necessidades do presente e trabalhando utilmente para criar e "antecipar" o futuro?" (2004c, p.190).

A essa pergunta, Gramsci responde mostrando que as comissões internas de fábrica são "órgãos de democracia operária que ocorre libertar 
das limitações impostas pelos empresários, aos quais ocorre infundir vida nova e energia. (2004c, p.191)". Elas “deverão ser amanhã os órgãos do poder proletário que substitui o capitalismo em todas as suas funções úteis, de direção e de administração. (ID. IBIDEM, p.191)”. Conforme apresentado por Dias (2000), as comissões internas eram comitês representativos dos operários dentro da fábrica. Criadas em 1906, elas se afirmaram como organismos capazes de exprimir os interesses imediatos dos operários italianos no próprio local de trabalho (normas disciplinares, horários, qualificações etc.). Com o passar do tempo e o desenvolvimento de suas atividades, sua ação política não demorou a produzir conflitos, seja com os empresários seja com os sindicalistas. Ressaltemos, portanto, que, antes mesmo de Gramsci e L'Ordine Nuovo começarem a estudar o problema das comissões internas, estas são já uma instituição há muito tempo reivindicada pelos operários.

A grande novidade apresentada por Gramsci em Democrazia Operaia reside justamente na colocação do problema das comissões internas como futuros órgãos do poder proletário na formação de uma democracia operária $^{4}$. Integradas com organizações camponesas, elas poderiam vir a funcionar como uma grande escola de formação política das massas, pois

[...] daria uma forma e uma disciplina permanentes às massas, $[. .$.$] habituando-as à tenacidade e à perseverança,$ habituando-as a considerarem-se como um exército em campo que tem necessidade de uma firme coesão se não quer ser destruído e reduzido à escravidão (GRAMSCI, 2004c, p.192).

$\mathrm{Na}$ fábrica, Antonio Gramsci vê o germe do Estado proletário, o núcleo da nova civilização de produtores a ser construída com a revolução comunista. Atento à configuração da luta de classes em Turim, no biênio $1919 / 1920$, ele percebe que as oficinas com suas comissões internas, os círculos socialistas, as comunidades camponesas e os comitês de bairro são

\footnotetext{
${ }^{4}$ Conforme documento publicado no dia 8 de novembro de 1919 , podemos observar que as propostas convergem para três eixos fundamentais: (i) todos os operários, sindicalizados ou não, poderiam ser eleitos; (ii) disciplinamento da classe trabalhadora por unidade de produção; (iii) ação política explicitamente anticapitalista e claramente revolucionária. (GRAMSCI, 2004c).
} 
germens de vida proletária. Para ele, a questão central era fazer com que estas instituições crescessem, se desenvolvessem e amadurecessem de modo que se tornassem órgãos de um verdadeiro contrapoder. $\mathrm{O}$ desenvolvimento dessas instituições, organicamente vinculado ao projeto revolucionário de constituição do Estado socialista, daria vida a uma autêntica experiência de auto-governo das classes proletárias (GRAMSCI, 2004c, p.191-192).

Concomitantemente ao trabalho político, pedagógico e organizativo para transformar os centros de vida proletária em órgãos de autogoverno das massas, Gramsci destaca o papel educativo do partido, ao propor a difusão da doutrina comunista na formação da consciência de classe dos trabalhadores italianos: "O Partido deve continuar a ser o órgão de educação comunista, o fogo da fé, o depositário da doutrina, o poder supremo que harmoniza e conduz às metas as forças organizadas e disciplinadas das classes operárias e camponesas.” (2004c, p.191).

A partir de 1920, sobretudo quando Gramsci analisa o fracasso das tentativas revolucionárias na Itália, a problemática do partido emerge com força. Até o final de 1918 e em meados de 1919, todavia, ecoa a tese de que o partido revolucionário exerce papel educativo ao potencializar o poder de classe do proletariado de modo a torná-lo dirigente já antes da conquista do poder governamental.

A necessidade de elaboração de trabalhos de formação política junto às massas decorre para Gramsci de sua compreensão acerca do desenvolvimento do processo revolucionário. Concebendo a revolução comunista como algo complexo e difícil, Gramsci não a identifica apenas como um ato insurrecional, que se decide com a tomada do poder político burguês. Para Gramsci, a revolução só é proletária e comunista quando consegue favorecer a (i) liberação de forças produtivas proletárias e comunistas elaboradas no seio da classe trabalhadora (conselhos), de modo que (ii) a expansão e a sistematização dessas forças sejam capazes de iniciar o trabalho necessário para estabelecer nova ordem nas relações de produção e distribuição. 
Considerando a falta de experiência do proletariado na arte de governar, Gramsci sublinha a necessidade de elevar sua consciência política, a fim de torná-lo capaz de participar ativa e permanentemente da formação do Estado Socialista.

Somente um proletariado educado politicamente, que não se entregue ao desespero e ao desalento diante dos reveses possíveis e inevitáveis, que permaneça fiel e leal ao seu Estado apesar dos erros que indivíduos possam cometer e dos retrocessos que as condições reais da produção possam impor, somente um proletariado assim poderá exercer a ditadura, liquidar a herança maléfica do capitalismo e da guerra e realizar a Internacional comunista (GRAMSCI, 2004a, p.255-256).

Note-se que o trabalho de formação de política entrelaça-se com a forma como Gramsci concebe o processo revolucionário, ou seja, a elevação da consciência política das massas é uma necessidade, porque a constituição do processo revolucionário, além de ser algo complexo e difícil, exige a participação qualificada do proletariado para a assunção do controle e gestão da nova sociedade. Segundo Gramsci (2004a, p.255 - 256), “não se muda de Estado com a simplicidade com que se muda de governo".

Na compreensão de Gramsci, a formação das condições subjetivas necessárias à práxis revolucionária passa pelo atendimento de duas condições básicas: de um lado, a superação da óptica puramente sindical, fundada sobre a busca de objetivos limitados e imediatos; por outro, a assunção de um ponto de vista universal, ou seja, voltado para um novo ordenamento econômico-político. Segundo Gramsci, a criação do Estado socialista não é um ato taumatúrgico, mas um fazer-se, um processo de desenvolvimento. Por sua natureza, exige uma disciplina diversa dàquela exigida pelo Estado burguês, que faz com que os trabalhadores tenham a ilusão de influir sobre as decisões políticas mais amplas. "Ao contrário [...], o Estado socialista exige a participação ativa e permanente dos companheiros na vida de suas instituições.” (GRAMSCI, 2004a, p.255). É por isso que sua constituição deve "se encarnar num tipo de organização que seja específico da atividade própria dos produtores e não dos assalariados escravos do capital.” (2004a, p.288). Não é casual o fato de que, a partir de 
julho 1919, o foco da atenção de Gramsci e de L'Ordine Nuovo se desloca, ainda que não univocamente, na direção da fábrica, na análise de seus mecanismos, no estudo dos fatores da produção.

A idéia de que a criação do Estado socialista relaciona-se ao surgimento, desenvolvimento e ampliação dos poderes das instituições proletárias, sobretudo daquelas calcadas na fábrica, vai ganhando força (o conselho como célula primária da organização comunista) (GRAMSCI, 2004a, p.272). A tática gramsciana de formação do Estado socialista a partir da modificação das reações sociais de produção coaduna-se com uma das teses marxianas centrais exposta no Prefácio à Crítica da Economia Política, segundo a qual o fator ontologicamente primário na explicação da história diz respeito à forma como os homens produzem e reproduzem sua vida material.

Em acordo com a idéia de que a nova sociedade será edificada a partir da transformação radical das relações sociais de produção organicamente à elevação da consciência de classe dos trabalhadores, Gramsci propõe a transformação do "chão da fábrica" numa verdadeira “escola das capacidades reconstrutivas dos trabalhadores." (GRAMSCI, 2004a, p.277). Trata-se, em suma, de um trabalho formativo que, organicamente ligado à posição que o trabalhador ocupa no processo produtivo, desencadeia um processo de educação no interior das unidades de trabalho; instaura uma prática de participação e discussão que efetivamente modifica as consciências; possibilita a ruptura com as relações e valores que sedimentam a sociedade capitalista; leva o operário a tomar consciência de sua situação de classe (DIAS, 2000, p.176; SCHLESENER, 2002, p.105). Esta constatação é importante porque afirma a exigência de pensar o desenvolvimento de suas idéias político-pedagógicas indissoluvelmente ligadas à problemática do mundo do trabalho.

O ano de 1920 será decisivo para os conselhos de fábrica, assim como marca um ponto de inflexão na posição de Gramsci. Em agosto de 1920, Gramsci se separa de Togliatti e Terracini e funda, juntamente com Vicenzo Bianco, Battista Santhià e Andrea Viglongo, o grupo "Educação 
Comunista", que se voltará para ações pedagógicas nas fábricas, em consideração ao potencial revolucionário hipotecado aos conselhos de fábrica. Eis aqui um novo ângulo para a compreensão das idéias de Gramsci sobre formação política. Se, anteriormente, tínhamos a noção de que os instrumentos de luta da classe trabalhadora deveriam ser complementados com órgãos educativos e culturais a fim de sedimentar a consciência de classe dos trabalhadores, a experiência teórico-prática dos conselhos levará Gramsci à proposição de que os trabalhadores se formam politicamente no e pelo trabalho.

Para Gramsci, os conselhos de fábrica deveriam substituir a figura do capitalista não apenas sob o plano simbólico, mas, sobretudo, sob o plano concreto e gerencial, ou seja, o controle operário deveria ser a demonstração da capacidade proletária de colocar adiante a produção, racionalizando-a e melhorando-a, o que demonstraria, na prática, sua capacidade de ser classe dirigente antes mesmo da tomada do poder governamental ${ }^{5}$. Ancora-se a idéia da fábrica como coração do Estado e do operário como elemento-base de edificação da sociedade socialista.

Os conselhos de fábrica seriam instrumentos profícuos de formação política por que permitiriam a formação de uma massa revolucionária que extrapolaria a luta econômico-corporativista (luta salarial, condições de trabalho, jornada de trabalho etc.), que questionaria em suas bases o ordenamento produtivo e distributivo capitalista. E mais: por entregar aos trabalhadores a responsabilidade direta da produção, eles criariam à psicologia do produtor, "do criador da história". Eis por que o "conselho é o mais idôneo órgão de educação recíproca e de desenvolvimento do novo espírito social que o proletariado foi capaz de gerar a partir da experiência viva e fecunda da comunidade de trabalho" (GRAMSCI, 2004a, p.289).

Em setembro de 1920, ante a resistência patronal de atendimento às reivindicações salariais e contra a vontade das organizações sindicais e do

\footnotetext{
5 A esse respeito, Dias faz uma observação fundamental: “A ação do conselho implica efetivamente o início da construção da hegemonia proletária [...]. Aqui está formulada, de fato, ainda que não plenamente, a teoria da hegemonia" (2000, p.181).
} 
PSI, os operários turinenses ocupam as fábricas metal-mecânicas e passam a gerir a produção. O movimento se estende aos estabelecimentos dos setores têxteis, químicos, de calçados e de borracha, totalizando cerca de 500 fábricas italianas. "Ato pedagógico por excelência, a tomada da fábrica coloca para o movimento a questão radical do exercício do poder, ainda que sob a forma de uma experiência limitada" (Grifos do autor, DIAS, 2000, p.213).

Na ocupação das fábricas, assiste-se a uma verdadeira reviravolta na ordem existente. De fato, não é um movimento de mero protesto, mas a refutação da exploração capitalista e a formação de uma "nova ordem". Nas palavras de Gramsci: "Hoje, com a ocupação operária, o poder despótico na fábrica foi quebrado." (2004c, p.222). Inicia-se a concretização de um movimento no qual a representação operária passa a ser uma emanação direta das massas: “... os operários, na luta, ocupam as fábricas e querem continuar a produzir, [...] os chefes sindicais não podem mais dirigir, [...] a massa deve resolver por si, com os próprios meios, com os próprios homens, os problemas da fábrica" (Op.cit, p.222).

As fábricas, efetivamente, passam a ser o locus da democracia operária. A experiência da autogestão, ainda que efêmera, mostra que os operários se formam, fundamentalmente, no e pelo trabalho: "um dia como este vale para os operários tanto quanto dez anos de atividade normal, de propaganda normal, de normal absorção de noções e conceitos revolucionários." (GRAMSCI, 2004c, p.222). Aqui, Gramsci evidencia que o exercício da autogestão produtiva (base para a expulsão da gerência capitalista da produção) é fundamental para a formação da classe trabalhadora como classe dirigente antes mesmo da tomada do poder governamental. Revela, ainda, que esse exercício assume importância fundamental na formação da consciência de classe dos trabalhadores, sobretudo porque contribui para o desenvolvimento de uma personalidade e uma vontade coletiva.

A ocupação das fábricas mostrará a Gramsci que este é um momento absolutamente indispensável para o desenvolvimento e a concretização do 
processo revolucionário. Revelará, contudo, que, por não controlar o poder estatal, é um poder limitado. Diz Gramsci: “... se a ocupação pura e simples das fábricas, por parte da classe trabalhadora, indica o grau de potência do proletariado, não produz em si, nem por si, nenhuma nova posição definitiva." (2004c, p.226). Infelizmente, não obstante o esforço dos operários italianos, o movimento de setembro foi derrotado. Dentre as razões que explicam o fracasso, destacam-se: (i) a crescente dificuldade de abastecimento de matérias-primas; (ii) a impossibilidade da distribuição das mercadorias; (iii) a divisão do movimento; (vi) a falta de capacidade de estabelecer redes eficazes de solidariedade entre a fábrica e o exterior; e (v) a recusa do PSI e dos sindicatos em participar diretamente do conflito.

Em "Cronache dell 'Ordine Nuovo'", artigo publicado no dia 2 de outubro de 1920, Gramsci (2004c, p.229 - 230) faz um balanço da ocupação das fábricas e aponta as contribuições daquela experiência para a constituição do processo revolucionário italiano. A primeira foi ter demonstrado que os conselhos de fábrica se mostraram como instituições revolucionárias vitais e necessárias à classe operária italiana. A segunda refere-se à necessidade de pôr a questão do conselho operário como fase absolutamente necessária ao processo revolucionário. Por fim, a estratégia dos conselhos não deixou de ser uma crítica radical à incapacidade das organizações tradicionais do proletariado (partidos e sindicatos), sobretudo porque se colocou contra a falta de democracia dessas organizações e contra o espírito burocrático que as governa.

A partir daí, a atenção de Gramsci se voltará cada vez mais para o papel que o partido comunista assume no processo revolucionário, assim como para a idéia segundo a qual a concretização da revolução socialista é mais complexa do que parece e que seu processo de preparação não é apenas econômico-político, mas também pedagógico e cultural. Segundo Schlesener (2005, p.43), “A experiência dos Conselhos foi fundamental para a elaboração posterior de uma concepção de partido, que se esboça na polêmica e no dissenso com Togliatti e se explicita em Cadernos do Cárecere”. 
Em 1921, Gramsci, juntamente com Amadeo Bordiga, rompe com o PSI e funda o Partido Comunista da Itália (PCI). Para Gramsci, um partido comunista deve: (i) possuir consciência exata da missão histórica do proletariado; (ii) saber guiar o proletariado para a realização de sua missão histórica; (iii) ser o partido das massas que querem se libertar da escravidão política e industrial pelos próprios meios, de modo autônomo; e (iv) ser o locus onde a revolta popular contra o Estado burguês encontre as forças organizadas capazes de iniciar a transformação do aparelho nacional de produção, no sentido de fazer dele não um instrumento de opressão plutocrática, mas um instrumento de libertação comunista. Essa reflexão se estenderá até os últimos dias de vida de Gramsci, sendo aprofundada nos célebres Quaderni del carcere.

\section{Referências bibliográficas}

DIAS, Edmundo. Gramsci em Turim: a construção do conceito de hegemonia. São Paulo: Xamã, 2000.

D’ORSI, Ângelo. Antonio Gramsci e la sua Torino (Introduzione). In: GRAMSCI, Antonio. La Nostra città futura. Scritti torinesi (1911 - 1922). Roma: Carocci Editore, 2004.

GRAMSCI, Antonio. Quaderni del carcere. Torino: Nuova Universale Einaudi, 1975 (Edizione critica dell'Istituto Gramsci di Valentino Gerratana)

GRAMSCI, Antonio. Cronache Torinesi (1913 - 1917). Torino: Einaudi, 1980. (A cura di Sergio Caprioglio).

GRAMSCI, Antonio. Escritos Políticos (1910 - 1920). Tradução de Carlos Nelson Coutinho. Rio de Janeiro: Civilização Brasileira, 2004a.

GRAMSCI, Antonio. La Nostra Città Futura. Scritti Torinensi (1911 - 1922). Roma: Carocci, 2004c (A cura di Angelo d'Orsi.).

HOBSBAWM, Eric. Era dos Extremos: o breve século XX: 1914 - 1991. Tradução de Marcos Santarrita. São Paulo: Companhia das Letras, 1995.

SCHLESENER, Anita Helena. Antonio Gramsci e a política italiana: pensamento, polêmicas, interpretação. Curitiba: UTP, 2005. 